\title{
UTOPIAS, RELACIONES DE PODER Y DESARROLLO DE LAS FUERZAS PRODUCTIVAS
}

\section{Pedro Narbondo (*)}

\section{ACCION SOCIAL, CONOCIMIENTO Y CONDICIONAMIENTO TECNICO}

El desarrollo se produce por la acción de los hombres en función de sus fines.

Por acción entiendo la definición que da Kant: «Acción significa la relación del sujeto de la causalidad con el efecto») (1).

La acción humana se produce o bien como resultado de reacciones instintivas, o bien como resultado de la aplicación de los conocimientos de los hombres a la utilización de las capacidades físicas de los hombres y -mediante estas capacidades físicas - de los objetos exteriores a los hombres.

Los conocimientos, cuya aplicación a las capacidades físicas y a los objetos exteriores a los hombres producen la acción, son conocimientos sobre los hombres y sobre los objetos materiales, y sobre lo que pueden hacer los hombres con sus cuerpos y con los objetos exteriores, y sobre lo que necesitan o creen necesitar y desean para existir y actuar, y sobre los efectos de las acciones que pueden realizar. Son, pues, necesariamente, conocimiento empíricos (2).

Esto, a su vez, implica que esos conocimientos se producen por mediación de las acciones por las cuales cada hombre se relaciona con los otros hombres y con el medio ambiente. Es decir, es por su acción y por las acciones de los otros que cada uno se conoce a sí mismo, a los otros y al medio ambiente.

El conocimiento es, pues, necesariamente posterior a las acciones. Sin embargo, a partir de los conocimientos de las acciones ya producidas los hombres pueden no sólo controlar conscientemente la reproducción de estas acciones, sino también pensar nuevos tipos de acciones.

Todos los conocimientos, cuya aplicación a las capacidades físicas humanas y a los objetos exteriores producen la acción de los hombres, son, en tanto que conocimientos empíricos, o verdaderos o falsos. Esto se constata por la mediación necesaria de la acción a la cual el conocimiento (el concepto) se refiere. Si los conocimientos son falsos la acción o bien no se produce, o bien produce efectos distin-

\footnotetext{
(*) Pedro Narbondo, Licenciado en Sociologia y DEA en CC. Políticas, Universidad de Paris X Nanterre. Investigador en el Dpto. de CC. Políticas y de la Administración de la Facultad de CC. Políticas y Sociología de la U. Complutentese de Madrid.

(1) M. Kant, Crítica de la razón pura. Ed. Porrúa, México, 1987, p. 125.

(2) M. Kant, Crítica de la razón pura, op. cit., pp. 135, 126 y 303.
}

tos a los que el sujeto de la acción esperaba. En ambos casos, mediante la acción a la que el concepto se refiere el hombre comprueba y obtiene conocimientos, es decir, conocer que las acciones no se producen o no se producen de la manera esperada, y conoce que el conocimiento que tenía de sus capacidades físicas y de los objetos materiales no humanos, o eran falsos o en algo fueron mal aplicados (3).

La técnica es la relación de adecuación de los medios en función de un fin (4).

Los fines son los efectos que los hombres buscan producir con sus acciones. Los conocimientos existentes, las capacidades físicas existentes y los objetos materiales existentes determinan las acciones técnicamente posibles y con ello determinan los fines que los hombres pueden alcanzar.

Pero el condicionamiento técnico de la acción implica no sólo que existan y se conozcan los medios para obtener los fines, sino también que los medios utilizados y los fines alcanzados sean técnicamente adecuados a la producción de la existencia y capacidad de actuar durante el tiempo de realización de la acción de los hombres que las realizan. Bien que no sean técnicamente incompatibles con la utilización de medios técnicamente adecuados a producir la existencia y capacidad de actuar, durante el tiempo de realización de la acción, de los hombres que las realizan, y si esos medios son realmente producidos y utilizados en ello. Igualmente los medios y los fines sólo pueden ser reutilizados y reobtenidos si se dan esas mismas condiciones de adecuación técnica con respecto a la reproducción de los recursos y de la existencia y capacidad de actuar de los hombres que realizan las acciones.

Y esto también es verdad para las acciones instintivas: si éstas no son adecuadas a producir-reproducir la existencia y capacidad de acción de los hombres que las realizan y los recursos necesarios, esas acciones instintivas no se pueden reproducir.

Por último, en la medida que los hombres viven en relación con otros hombres el condicionamiento técnico no existe sólo en y por la acción de cada hombre, es decir, por las características de los medios utilizados, de los fines buscados y de las consecuencias de medios y fines utilizados y obtenidos por cada hombre sobre sí mismo, sino que existe también en y por la relación con los otros hombres. Es decir,

(3) K. Popper, Conocimiento objetivo. Tecnos, Madrid, 1982, p. 72

(4) M. Weber, Economía y sociedad. Fondo de Cultura Económica, México, 1922, pp. 47 y ss. y Essais sur la théorie de la science, Plon, París, 1965, pp. 456, 457, 460, 461, 462. 
existe por los efectos de las acciones de los otros sobre los medios, los fines y la existencia y capacidad de acción de cada hombre.

\section{PENSAMIENTO UTOPICO Y ACCION SOCIAL}

Una utopía es el pensamiento de un modelo ideal de sociedad (o de parte de ella) no existente. En el entendimiento corriente y en la definición clásica los modelos utópicos son identificados como aquellos cuya realización es imposible (5). Sin embargo, en una acepción más favorable, que últimamente ha cobrado fuerza en el pensamiento de izquierda, una utopía no es un fin imposible, sino un fin aún no realizado que orienta la acción de los actores descontentos con el desarrollo de la sociedad existente. Coincido con Sartori en que esta nueva definición lo único que aporta es confusión. Ahora bien, puesto que la confusión está creada tomaré la acepción más reciente y favorable para deliminar las características del pensamiento y de la mentalidad utópicos prácticos. Aún en este sentido no se trata de cualquier tipo de orientación de los conocimientos y de la acción en función de fines aún no realizados, sino un tipo específico que se caracteriza por:

a) el pensamiento utópico práctico sólo piensa el modelo ideal de sociedad deseado pero no es capaz de diagnosticar correctamente los problemas concretos y las condiciones y medios sociales necesarios para resolverlos. En palabras de Mannheim (que es, con E. Bloch, quien ha planteado la definición más favorable):

« Su (de los utópicos) pensamiento es incapaz de diagnosticar correctamente una situación real de la sociedad, no les interesa en forma alguna la realidad, antes bien se esfuerzan en su pensamiento por cambiar el orden vigente. Su pensamiento nunca es un diagnóstico de la situaciór puede servir para orientar la acción» (6).

y b) para la mentalidad utópica el modelo ideal que orienta los conocimientos y la acción es válido por el solo hecho de ser la expresión de un deseo predominante sin tomar en consideración los conocimientos empíricos sobre la realidad social. En palabras de Mannheim:

«En la mentalidad utópica lo inconsciente colectivo guiado por una apasionada representación y por una decidida voluntad de acción oculta ciertos aspectos de la realidad. Vuelve la espalda a todo aquello que debilitaría su creencia o paralizará su deseo de cambiar las cosas» (Ibid., 6). «Se puede hablar de una mentalidad utópica sólo cuando la configuración de la utopía en cualquier tiempo constituye no sólo una parte vital del contenido de dicha mentalidad, sino cuando por lo menos en su tendencia general impregna completamente esa mentalidad [...] Lo que determina la su-

(5) G. Sartori, Teorias de la democracia. Alianza Ed., Madrid, 1989, Vol. I, pp. 87, 88. K. Mannheim, Ideología y utopía. Fondo de Cultura Económica, México, 1987, p. 172.

(6) K. Mannheim, op. cit., pp. 35-36. Véase también 169, 171. J. C. Davis, Utopía y la sociedad ideal. Fondo de Cultura Económica, México, 1985, pp. 369-371. cesión, el orden y la valoración de las experiencias aisladas es el elemento utópico, es decir, la naturaleza del deseo predominante» $(7)$.

Partiendo de estas dos características que según la definición más favorable distinguen al pensamiento y a la mentalidad utópica resulta que éstos no son la única vía o método para pensar y actuar en función de fines aún no realizados. Un pensamiento que elige y define un fin como respuesta a problemas concretos conocidos empíricamente, porque ya se han planteado o porque ya se manifiestan las tendencias que permiten prever que se plantearán, y en función del cual diagnostica o intenta diagnosticar, mediante conocimientos empíricos, los medios y las condiciones sociales de su realización, y que está dispuesto a rectificar según los datos de la experiencia, no es un pensamiento utópico, sino un pensamiento que formula hipótesis sobre problemas y sobre la utilidad y posibilidad de resolverlos. En tanto que el fin es pensado y formulado por combinación de elementos empíricos sobre las condiciones y los medios por los cuales se realiza, el pensamiento que indica el fin indica, al mismo tiempo, las acciones materiales de su realización, y con ello de su contrastación empírica. El éxito o el fracaso en la producción de las acciones, la producción o no producción de los efectos esperados - es decir, la solución, o comienzo de solución, de los problemas concretos-, y las consecuencias de estos efectos sobre el hombre y el medio ambiente son el mecanismo de verificación empírica de los conocimientos por los cuales se definió el fin. Así, por mediación de un pensamiento que combina conocimientos empíricos sobre problemas existentes, o previstos, y medios y condiciones sociales se puede actuar en función de un fin todavía no realizado, y al actuar verificar empíricamente, y rectificar si así corresponde, los conocimientos en los que se funda la elección de los medios y también del fin. Esto último por la constatación de su adecuación para resolver los problemas planteados y por la constatación de sus efectos derivados. Este tipo de orientación de los conocimientos y de la acción no corresponde a las características del pensamiento y de la mentalidad utópicos, ya que en todo momento se piensan, con disposición a rectificar si así corresponde, conocimientos verificables empíricamente sobre condiciones y medios de acción en función de resolver problemas concretos, mientras que el pensamiento utópico piensa el modelo ideal de sociedad sin tener en cuenta el «diagnóstico correcto de la situación real», y para la mentalidad utópica el único criterio de validez del modelo ideal es su correspondencia con «el deseo predominante».

Esta diferencia entre el pensamiento no utópico sobre fines aún no realizados con respecto al pensamiento utópico no tiene la más mínima relación con la cuestión de la rapidez o lentitud del proceso ni el tamaño o amplitud de los objetivos. La transformación de una institución particular no implica un método diferente de conocimiento de problemas, medios, condiciones y fines que la transformación de todo un régimen autoritario en democrático (o viceversa). $\mathrm{O}$ de

(7) K. Mannheim, op. cit., p. 183, véase también pp. 84, 85, 86, 92. J. C. Davis, op. cit., 365 . Sobre la posición de M. Weber con respecto a los modelos utópicos (ideal tipos) como valor supremo de los juicios prácticos, véase Essais, op. cit., pp. 180, 181, 183, 192, 193. 
un Estado de Bienestar en un Estado liberal (o viceversa). En todos los casos las acciones dependen del diagnóstico correcto de las condiciones sociales, de los medios y de la velocidad y amplitud de las acciones que el problema diagnosticado y tomado como fin exija o permita.

Cabe preguntarse entonces por qué la izquierda, a nivel político e intelectual, ha ido progresivamente autodefiniendo sus fines, en lo que tienen de específicamente de izquierda como ideales morales utópicos, y su pensamiento como un pensamiento cuyo rol específico es la crítica moral de la realidad a partir y en función de ideales utópicos. Creo que la respuesta se puede obtener mediante el método de comprensión de M. Weber por el cual se compara la coherencia de fines ideales, acciones reales y consecuencias de éstas (8).

Una respuesta podría ser que ante una sociedad dominada por el conocimiento empírico conservador que se limita a reflejar y reproducir la realidad social existente, y ante el dogmatismo del pensamiento de izquierda tradicional, el rol de un pensamiento comprometido con el objeto de la emancipación de los dominados es el motivar y orientar el conocimiento y la acción mediante la crítica de la sociedad existente en función de fines ideales deseados y no realizados en ella.

\section{Esta respuesta no me parece válida por tres razones:}

1) La primera razón es que si el pensamiento de izquierda se autolimita al rol utópico no puede guiar correctamente las acciones reales. Sólo lo podrá hacer si deja de ser utópico, es decir si deja de ser un pensamiento incapaz de conocer y diagnosticar correctamente las condiciones y medios reales de acción. Por lo tanto, si el objetivo de la izquierda es transformar realmente la sociedad el carácter utópico del pensamiento no es algo a reivindicar, sino a superar. Sin duda la mentalidad utópica es síntoma y expresión de aspiraciones y deseos no satisfechos. Pero es también síntoma y expresión de la falta de capacidad de los sectores receptivos a las utopías para producir conocimientos empíricos sobre las condiciones y los medios para actuar en función de sus deseos y aspiraciones. Y sin duda el pensamiento de izquierda tiene que acercarse y recoger las vivencias y esperanzas de los sectores con menos capacidad de acción, es decir, acercarse y hablar el lenguaje de lo que Gramsci llamaba el «sentido común» (9). Pero para que esas aspiraciones se transformen en acciones reales es necesario producir y poner en práctica conocimientos empíricos sobre condiciones y medios reales en funciones de las necesidades y problemas concretos. Si no es así, por más insatisfacción que exista, las tentativas de acción conducirán al fracaso y a la impotencia, ya que la acción sólo puede alcanzar el fin

(8) Weber, Essais, op. cit., pp. 125, 126, 188, 189, 191, 194, 298-323, 310; Economía y sociedad, op. cit., pp. 6, 9, 19, y K. Popper, Conocimiento objetivo, op. cit., pp. 154-179.

(9) A. Gramsci, Gramsci dans le texte. Ed Sociales, París, 1977, pp. 134, 135, 136, $308,309,586,587$. Sobre la manera como Gramsci consideraba las utopías, véase 276,277 , donde las identifica con concepciones metafísicas sobre las cuales la religión es la más clara expresión, que resuelven de manera mitológica y con un mundo imaginario las contradicciones reales de la vida histórica. Creo, sin embargo, necesario puntualizar que en mi criterio, a pesar del gran aporte que significa la insistencia de Gramsci sobre los aspectos culturales de la acción y el cambio social, a su concepción de la filosofia de la praxis como autoconciencia verdadera del verdadero sujeto de la historia le corresponde un tipo de crítica similar al que a continuación hago al dogmatismo del pensamiento utópico. Sobre Gramsci y utopia véase también pp. 415,417 . buscado si los conocimientos sobre el fin, los medios y las condiciones reales son verdaderos y son correctamente puestos en práctica. Puesto que lo que caracteriza el pensamiento utópico es la incapacidad para diagnosticar correctamente problemas, condiciones y medios resulta que el pensamiento de izquierda, como cualquier pensamiento, sólo puede guiar exitosamente la acción consciente en la medida que no corresponda, o deje de corresponder, a la definición (la más favorable) del pensamiento utópico.

2) La segunda razón es que no me parece que el pensamiento utópico permita superar el dogmatismo en la orientación del conocimiento y de la acción.

El ideal utópico que da sentido práctico a los conocimientos sobre acciones no es el mero principio regulativo de todos los conocimientos, a saber: que todo conocimiento no está completo hasta conocer la totalidad de las condiciones de un condicionado dado (10). Este principio no dice nada sobre la orientación material del conocimiento y de la acción, mientras que la utopía es un modelo de sociedad ideal aún no existente en función del cual se orientan ambos.

Ahora bien, el pensar y formular modelos teóricos que orienten el conocimiento de lo aún no conocido no es específico y exclusivo del pensamiento utópico práctico (ni del pensamiento de izquierda), ya que la ciencia y más generalmente todo conocimiento empírico se propone conocer lo aún no conocido, y el método científico o racional implica la formulación de teorías hipotéticas. Lo que caracteriza al pensamiento utópico práctico es que el modelo ideal de sociedad es el fin o valor supremo que orienta moralmente el conocimiento y la acción.

Pero el ideal utópico como fin supremo de los juicios morales no es un mero principio regulativo formal como el imperativo categórico kantiano, ni un ideal abstracto como la idea kantiana del bien supremo, sino un ideal concreto, o sea, un sistema de valores constituido por el modelo de sociedad deseado como fin supremo (11). Sin embargo, la orientación del conocimiento y de la acción en función de valores no es, tampoco, específico y exclusivo del pensamiento utópico (ni del pensamiento de izquierda), por la sencilla razón que ningún pensamiento y ninguna acción puede no orientarse por valores. Incluso la orientación del pensamiento y de la acción en función de producir conocimiento científicos (12), e incluso la orientación en función del éxito (13), implican, necesariamente, en el momento de la elección de esas orientaciones una opción de valor. Y una vez realizadas esas opciones básicas, la elección de los aspectos de la realidad a conocer (14) y de las características materiales del éxito buscado (15) implican, necesariamente, opciones de valor.

(10) M. Kant, Razón pura, op. cit., pp. 178, 179, 180.

(11) Véase la crítica de Bloch a Kant, El principio esperanza, Aguilar, Madrid, 1977, p. 238. M. Kant, Crítica de la razón práctica, op. cit., pp. 45 y 50, 68, 154, 157, 162. Crítica de la razón pura, pp. 179, 348, 350.

(12) M. Weber, Le savant et le politique. Plon, París, 1959, pp. 100, 101. Essais, op cit., $135,136$.

(13) M. Weber, Essais, op. cit., 437, 438, 439, 441.

(14) Kant, Crítica de la razón práctica, op. cit., p. 171. M. Weber, Essais, op. cit., $126-136,140,152,153,162,163,167,168,173,434$.

(15) M. Weber, Economia y sociedad, op. cit., p. 64, y Essais, op. cit., pp. 128, 151 , $166,435,441,442,457,458,459,460,461,462$. 
Tampoco lo específico del pensamiento utópico es el ser expresión consciente de los fines de la acción. Toda acción intencional implica representación consciente del fin. Y las acciones orientadas de la manera que $\mathrm{M}$. Weber llama racional en finalidad implican, además, analizar el fin, las condiciones y medios de su realización, y sus consecuencias.

En cambio lo específico del pensamiento utópico práctico es que el único criterio de validez del modelo ideal de sociedad en función del cual juzga y critica moralmente los conocimientos y las acciones es el ser la expresión de un deseo predominante. Los medios y las acciones son seleccionados y puestos a prueba en la práctica en función de su adecuación con respecto al modelo ideal utópico. Pero ningún conocimiento empírico puede poner en cuestión la validez de éste. Cualquiera que sean los problemas, las condiciones y los problemas sociales reales y conocidos empíricamente sólo son válidos y pertinentes aquellos aspectos de la realidad que refuerzan el deseo del fin utópico y por lo tanto, en palabras de Mannheim, la mentalidad utópica "oculta ciertos aspectos de la realidad. Vuelve la espalda a todo aquello que debilitaría su creencia».

En ese sentido, si lo específico del pensamiento de izquierda es el ser utópico práctico su especificidad no consiste en que se guíe por modelos teóricos, ya que eso es común con el pensamiento científico o racional, ni en que se oriente por valores, ya que eso es común a todo pensamiento, sino en que es un pensamiento en el cual el único criterio de validez del modelo utópico de sociedad que constituye el valor supremo es el de su coherencia interna como expresión de los deseos que el propio pensamiento utópico define como moralmente justos porque son adecuados al modelo utópico de sociedad.

Lo cual no quiere decir que su especificidad consista en que funde su validez en la coherencia interna, sino en que su único criterio de validez es la coherencia interna. Toda teoría social y todo pensamiento racional sobre sociedades (existentes o no), sólo son válidos, y sólo pueden ser verdaderos, si son coherentes consigo mismos. Pero las teorías, o pensamientos racionales hipotéticos sobre modelos de sociedad son ellos mismos susceptibles de contrastación empírica, y revisables según sus efectos sobre la producción-reproducción de la existencia y capacidad de acción de los hombres, y sobre el medio ambiente en el cual y del cual viven. En cambio, en el pensamiento utópico práctico las acciones y los conocimientos empíricos son juzgados por su adecuación a un modelo ideal de sociedad que es válido, con independencia de toda contrastación empírica, por su coherencia en la formulación de los deseos que corresponden al modelo utópico de sociedad, y que, como tales, dan identidad al verdadero sujeto, o sujetos, del devenir. Así, por ejemplo, E. Bloch (16) identifica al marxismo con la au-

(16) E. Bloch, El principio esperanza, op. cit.: «El contenido del acto de la esperanza es en tanto que clarificado conscientemente, en tanto que explicitado escientemente, la función utópica positiva, el contenido histórico de la esperanza, representado primero en imágenes, indagado enciclopédicamente en juicios reales, es la cultura humana referida a su horizonte utópico concreto... En la esperanza consciente y sabida no hay nada débil, sino, una voluntad que lo penetra; debe ser asi, y tiene que ser así», pp. 135-136 ... «La isla solitaria en la que al parecer se encuentra la utopía puede ser, sin duda, un arquetipo (para Bloch los arquetipos toconciencia, es decir la identidad consciente, del verdadero sujeto de la historia, el proletariado; definido por el propio marxismo como la clase cuyo interés es la abolición de todas las clases, o sea, la construcción de la sociedad comunista que es el final de la historia de la necesidad y el comienzo de la historia de la libertad. Como tal el marxismo es el conocimiento verdadero, ya alcanzado y conocido como verdadero, de la utopía concreta que constituye el supremo valor que da sentido a las acciones y al conocimiento (17).

3) La tercera razón es que no me parece un pensamiento de izquierda que se defina a sí mismo y a sus ideales como utópicos sea capaz de motivar la voluntad de conocer y actuar en función de transformar la sociedad. El pensamiento de izquierda, tanto en su versión comunista como en su versión socialdemócrata, contribuyó a formar y desarrollar en los siglos XIX y XX un movimiento social y político alternativo y transformador de la realidad (con todos sus errores, defectos y carencias), en la medida que no aceptaba que se lo caracterizara como utópico, sino que se autoidentificaba y se presentaba, quizá por error o ignorancia, como un pensamiento que proponía medios para resolver en las condiciones sociales reales lo que consideraba los problemas existentes y tendencias de la socidad capitalista. No creo, en cambio, que los hombres, cualesquiera que sean su extracción social y su capacidad cultural, se puedan sentir motivados a orientar su acción, incluyendo las acciones de búsqueda y producción de conocimientos, por un pensamiento que se autoidentifica como un pensamiento utópico, o sea, según la definición más favorable de Mannheim, un

son modelos referidos a un pasado real o legendario, véase 148-155) pero en ella actúan con mayor intensidad las figuras ideales de la perfección anhelada, en tanto que despliegue libre o también ordenado del contenido vital... Lo ideal no puede de ninguna manera ser adoctrinado o rectificado por meros hechos, es característico de su esencia el encontrarse en relación tensa con la mera facticidad llegada a ser. No obstante lo cual lo ideal si de algo sirve, mantiene contacto con el proceso del mundo, en el que los llamados hechos son abstracciones fijadas y objetivadas. En sus anticipaciones, si son concretas, lo ideal tiene un correlato en los contenidos de esperanza de la latencia-tendencia; y este correlato hace posibles ideales éticos como modelos, ideales estéticos, como pre-mostración, que apuntan a un algo que va a hacerse posiblemente real (Sobre el concepto de posibilidad real según Bloch, véase $224,232,234$ : «posible real y su esencia... según la anticipación concretísima de Marx... es la abolición de la alienación en el hombre y en la naturaleza»). Estos ideales rectificados y adecuados por la función utópica son en su conjunto los ideales de un contenido del mundo y del yo humanamente apropiado... El socialismo se ha convertido por Marx, y por Lenin mismo, en el estadio correspondiente, en un ideal que por razón de su solidez mediada, enardece no menos, sino más que el ideal abstracto. Y precisamente el nuevo ideal político, el reino de la libertad como summum bonum político, es tan poco ajeno a la historia conformada conscientemente que representa en su concreción la finalidad de ésta, el último capitulo de la historia del mundo» pp. 163-164. Véase también 277 y 272 donde Bloch rechaza el trial-and-error method y K. Mannheim, Ideología y utopía, op. cit., 183, 184, 216.

(17) Y no critico con esto al marxismo, sino al pensamiento utópico, y al marxismo en lo que tenía y tiene de pensamiento utópico. En ese sentido, en la versión positivista y antiutópica de sus fundadores, y dentro de lo ingenua y falsa (aunque hay que tener en cuenta que el pensamiento científico no se define por ser verdadero, sino por el hecho de que acepte y busque la contrastación empírica de los modelos teóricos), y no exenta de dogmatismos (como, por otra parte, ninguna teoría o pensamiento humano), que pudiera ser esa pretensión, el marxismo se autoidentificaba como una teoría científica y como tal se preocupaba y se interesaba sobre todo y ante todo en la producción de conocimientos empíricos sobre los medios y condiciones reales de la transformación social, y con ello aceptaba y reivindicaba la verificabilidad empírica del modelo teórico con el cual juzgaba y criticaba la realidad. K. Marx, Le Capital, Ed. Sociales, París, 1977, pp. 13, 14, 20-22; K. Marx, La guerra civil en Francia, Instituto Cubano del Libro, La Habana, 1973, p. 95; K. Marx, Contribution à la critique de l'économie politique, Ed. Sociales, París, 1977, pp. 165, 166, 167, 170, 171, 172, 224, 225; K. Marx y F. Engels, Manifest du Parti Communiste, Ed. en langues étrangères, Pekín, 1977, pp. 70-74, y F. Engels, Anti-Dühring, Ed. Sociales, París, 1977, pp. 49, 119, 120, 121, 233, 294, 295,302 . 
pensamiento «incapaz de diagnosticar correctamente la situación real de la sociedad». No niego con esto que, como sostiene este autor, el pensamiento utópico puede motivar la acción. Pero la motiva en tanto en cuanto los actores utópicos no son conscientes de que su pensamiento es utópico. Es el investigador quien diagnostica el carácter utópico de la mentalidad y del pensamiento porque constata que la fuerza del deseo predominante hace que determinados actores actúen a pesar de que, según la constatación del investigador, su pensamiento es incapaz de diagnosticar correctamente las condiciones y los medios de acción. Pero los actores utópicos no son conscientes del carácter utópico que atribuye el investigador a su mentalidad y pensamiento. Si toman conciencia de ello toman conciencia de que actúan motivados por el deseo de un fin sin ser capaces de diagnosticar correctamente los problemas, las condiciones y los medios reales de acción. Y esta toma de conciencia o bien lleva a intentar superar el pensamiento y la mentalidad en lo que tienen de utópico, o bien desmotiva e inhibe la acción, por la sencilla razón de que los hombres, cualquiera que sea su extracción social y su capacidad cultural, tienen bastante claro, sea por reflexión teórica, sea por experiencia, que si no se diagnostican correctamente los problemas, las condiciones y los medios, las acciones tienen muy pocas posibilidades no sólo de alcanzar los fines aún no realizados, sino de producir y reproducir la existencia y capacidad de conocer y actuar del sujeto, o de los sujetos, que las intentan realizar. Y no niego con esto la fuerza de los sueños y de los ideales para motivar la acción. Pero los sueños o ideales motivan acciones reales cuando no se los identifica como utopías. Podrán ser identificados como utópicos por quien los critica y/o actúa en función de ellos. Pero quien actúa realmente en función de ellos no cree, quizá por error o ignorancia, que sean utópicos, sino que cree que son fines aún no alcanzados en función de los cuales pone en práctica sus conocimientos empíricos sobre condiciones y medios reales. Así, por ejemplo, los que actúan para satisfacer las necesidades de los más necesitados a través de la asistencia social no consideran que ese fin concreto sea una utopía, ya que conocen los medios para realizarlo y los ponen, o intentan ponerlos, en práctica en las condiciones adecuadas. En cambio, con respecto a los fines que consideran que hoy por hoy son utópicos, por ejemplo la transformación de la estructura de poder, no actúan porque en ese terreno no conocen, o creen que no conocen o que no existen, las condiciones y los medios para actuar con éxito. (Esto es sólo un ejemplo, por lo tanto se puede invertir el rol de fin considerado utópico y de fin considerado no utópico.) Es decir, cuando los hombres realmente actúan en función de un fin es porque conocen, o creen conocer, las condiciones y los medios para alcanzarlos, y como tal no consideran que esos fines sean utópicos, sino simplemente fines aún no realizados. En cambio, cuando creen que sus sueños o ideales son utópicos consideran que, por ahora, no se pueden realizar, porque aún no se conocen o no existen las condiciones y los medios de su realización, y por lo tanto son sueños o ideales que sólo sirven como consuelo o fuente de satisfacción estético-ética que permite sobrellevar, manteniendo una identidad propia, la adaptación sin transformación a lo que existe.
Como no creo que sea posible actuar en función de un fin guiado por un pensamiento incapaz de conocer las condiciones y medios de acción, y como no creo que sea posible superar el dogmatismo de un pensamiento cuyo único criterio de validez sea la coherencia consigo mismo, y como no creo que se pueda motivar el conocimiento y la acción transformadores y no dogmáticos autodefiniendo su propio pensamiento con esas dos características, creo que se puede decir (siguiendo el método comprensivo de $\mathrm{M}$. Weber) que la autoidentificación progresiva de la izquierda con el pensamiento utópico práctico ha jugado en las últimas décadas, y juega actualmente, el rol de ideología que legitima la orientación del conocimiento empírico, y de la acción de los partidos políticos, movimientos intelectuales, etcétera, identificados con la izquierda en función de la adaptación, de buena o de mala gana, al sistema del capitalismo neoliberal triunfante.

El hecho de que la izquierda defina su propio pensamiento como utópico es expresión y resultado de la hegemonía creciente del pensamiento neoliberal. Un sistema de pensamiento es hegemónico en tanto que los sistemas competidores aceptan explícita o implícitamente su mayor racionalidad y aceptan, explícita o implícitamente, pensarse a sí mismos bajo los conceptos del sistema hegemónico. En tanto que el pensamiento de izquierda se piensa a sí mismo como utópico acepta la caracterización - rechazada con éxito mientras tuvo dinámica hegemónica- que de él ha intentado hacer desde siempre el pensamiento liberal y neoliberal. Es decir, acepta pensarse a sí mismo con los conceptos del pensamiento que se ha vuelto hegemónico. Y con esto el pensamiento de izquierda pasa a jugar un rol legitimador de la adaptación pasiva de los sectores sociales que no se identifican con el pensamiento neoliberal hegemónico.

Este rol legitimador tiene grosso modo dos caras, como dos caras tiene la evolución y suerte de los sectores políticos, económicos y culturales identificados con la izquierda. Para los sectores con menores capacidades de acción el desarrollo del capitalismo neoliberal se ha traducido y se está traduciendo por la marginación o pérdida relativa de capacidad de competir con éxito, a nivel político, económico y cultural, en función de satisfacer sus necesidades e intereses. Para estos sectores las utopías permiten sobrellevar la necesaria, para sobrevivir, adaptación pasiva, escapando de manera imaginaria de la impotencia para satisfacer sus necesidades e intereses mediante la identificación con fines y modelos ideales que, en tanto que no se conocen los medios de su realización, y con ello de verificación empírica, nunca podrán ser desmentidos por la realidad social.

Por el otro lado para los sectores económicos, políticos, intelectuales, identificados con la izquierda, pero con capacidades de conocer y actuar relativamente desarrolladas, el neoliberalismo no se traduce en marginación, sino que les abre posibilidades de mayor recompensa, política, económica y cultural, por sus capacidades de acción. Para estos sectores la identificación de los fines de izquierda como ideales utópicos justifica y legitima su estrategia de adaptación al sistema neoliberal (no exenta de conflictos como toda acción social), al tiempo que les mantiene una identidad de izquierda que les permite competir en la arena polí 
tica y cultural con los sectores conservadores y neoliberales, sin que esa competencia ponga en peligro la estructura de poder político, económico y cultural en la cual, mediante esa competencia, se integran.

Para ambas caras de la izquierda el significado de la identificación de los fines de izquierda con ideales utópicos creo que se puede sintetizar parafraseando libremente (y sin su concisión y elegancia) el «pesimismo de la inteligencia, optimismo de la voluntad» de Gramsci (18), por la fórmula: «utopismo del pensamiento, adaptación pasiva de la acción, conformismo de la inteligencia y buena conciencia de la voluntad». Puesto que la única y verdadera alternativa es un modelo ideal de sociedad del cual no se conocen los medios de su realización en el presente sólo es posible realizar las acciones adecuadas y adaptadas al sistema social existente, por lo tanto lo inteligente es actuar en función de los fines posibles y aceptables en el sistema existente, lo cual es perfectamente legítimo, ya que en este momento es imposible actuar en función de otros fines, ya que no se conocen los medios para ello.

Y con la legitimación de la acción adaptativo-pasiva el pensamiento utópico refuerza al pensamiento neoliberal como único instrumentalmente racional. Cualquier alternativa al capitalismo neoliberal es utópica, la izquierda misma no sólo lo reconoce, sino que lo reivindica como seña de identidad. Por lo tanto, la única actitud realista e instrumentalmente racional es el mantenimiento y perfeccionamiento del capitalismo neoliberal. Lo que, a su vez, da como resultado que los problemas de decisión sobre la orientación del desarrollo económico y cultural, y sobre la distribución de los recursos políticos, económicos y culturales sean identificados como problemas técnicos para los cuales, en este momento, sólo existe una solución técnicamente adecuada (aunque en el terreno de las utopías se pueden imaginar infinitas variantes).

Lo cual creo que es absolutamente cierto en cuanto a que son, como todos los problemas referidos a la acción, problemas técnicos. Pero es falso en cuanto a que para los distintos individuos que componen la sociedad, y para todas las sociedades existentes en la actualidad, exista una misma solución técnicamente adecuada a sus necesidades e intereses. Y me parece falso porque la adecuación técnica depende estrictamente del fin en función del cual se utilicen los medios. Como los individuos (y los sectores sociales y las distintas sociedades) tienen en cada momento necesidades e intereses distintos, y en parte contradictorios debido a la escasez relativa de recursos, resulta que en cada momento no existe un solo fin que determine la adecuación de los medios, sino distintos fines, es decir, diferentes necesidades e intereses. Como la técnica es la relación de adecuación de los medios a la producción del fin resulta que en cada momento existen distintas acciones técnicamente adecuadas a los diferentes fines y necesidades de los diferentes individuos (o sectores sociales o sociedades).

(18) Más exactamente de Romain Rolland, A. Gramsci, Gramsci dans le texte, op cit., p. 75.

\section{SELECCION DE LOS FINES DE LA ACCION SOCIAL Y RELACIONES DE PODER}

Cada hombre elige los fines de sus acciones a partir y en función de sus deseos y creencias (19). Como los recursos para actuar son relativamente escasos y como los hombres tienen distintos conocimientos e intereses sobre la distribución y utilización de los recursos o medios, resulta que los fines y las acciones correspondientes son seleccionados por los hombres en el proceso de lucha, en el cual produciendo la realidad social, se producen, se ponen a prueba y se seleccionan los conocimientos empíricos sobre medios y fines.

Entiendo por lucha la definición que M. Weber da:

«Debe entenderse que una relación social es de "lucha" cuando la acción se orienta con el propósito de imponer la propia voluntad contra la resistencia de la otra y otras partes. Se denominan "pacíficos" aquellos medios de lucha donde no hay violencia física efectiva. La lucha pacífica llámase "competencia" cuando se trata de la adquisición formalmente pacífica de un poder de disposición propio sobre probabilidades también deseadas por otros. Hay competencia "regulada" en la medida que esté orientada, en sus fines y medios, por un orden determinado. A la lucha (latente) por la existencia que, sin intenciones dirigidas contra otros, tiene lugar, sin embargo, entre individuos como entre tipos de los mismos, por las probabilidades existentes de vida y de supervivencia, la denominaremos "selección": la cual es "selección social" cuando se trata de probabilidades de vida de los vivientes o "selección biológica" cuando se trata de supervivencia de tipo hereditario... Según enseña la experiencia la lucha es ineludible de hecho en el sentido de "selección" y lo es en principio en el sentido de "selección biológica". La selección es "eterna" porque no hay manera de imaginar medio alguno para descartarla de modo total (sólo sería posible de modo teórico y utópico). Hay que separar, naturalmente, de la lucha de los individuos por las probabilidades de vida y supervivencia, la lucha y selección de las relaciones sociales. Ahora bien, estos conceptos sólo pueden usarse en un sentido metafórico. Pues, las "relaciones" sólo existen como acciones humanas de determinado sentido. Por tanto, una lucha o selección entre ellas significa que una determinada clase de acción ha sido desplazada en el curso del tiempo por otra, sea del mismo o de otros hombres. Lo cual es posible de diversas maneras» (20).

El resultado de la lucha - pacífica (competencia) o violenta, consciente o latente (selección) - en la que se eligen y seleccionan los fines, es efecto del poder relativo de los hombres formado y puesto a prueba en esa lucha.

Por poder entiendo la capacidad de los hombres de realizar por coerción fáctica sus fines en la relación con otros

(19) J. Elster, Uvas amargas. Ed. Península, Barcelona, 1989, pp. 11-24, y El cambio tecnológico. Ed. Gedisa, Barcelona, 1990, p. 66.

(20) M. Weber, Economia y sociedad, op. cit., pp. 31 y 32 . 
hombres (21). Por coerción fáctica entiendo la acción por la cual un hombre, por voluntad consciente o como efecto no buscado de su acción, obliga o impide actuar a otro privándole de, o evitando que obtenga o utilice, los medios de existencia y acción (22).

La capacidad de un agente de imponer sus propios fines por coerción está constituida por su capacidad técnica de acción puesta en práctica, en relación a los fines y a la capacidad puesta en práctica de los otros hombres con los cuales se relaciona al actuar. Y esa capacidad técnica existe por los conocimientos empíricos de los hombres aplicados al control y utilización de sus capacidades físicas de acción y de los objetos materiales.

Partiendo de lo que los hombres necesitan para actuar en relación con otros hombres se pueden definir tres fuentes o medios fundamentales de poder (23). Puesto que toda acción necesita recursos materiales el control de éstos constituye una fuente de poder. Puesto que la violencia física puede impedir la existencia y la acción de los hombres el control de su ejercicio, constituye otra fuente de poder. $\mathrm{Y}$ puesto que los hombres necesitan conocimientos para actuar, el control de la comunicación de conocimientos constituye otra fuente de poder.

El poder económico se basa en el control efectivo de los recursos materiales. Este control se basa en la puesta en práctica de los conocimientos empíricos de un hombre en las acciones necesarias para controlar los recursos materiales en cualquier tipo de acción.

El poder político se basa en el control efectivo, mediante la puesta en práctica de los correspondientes conocimientos, de los recursos materiales y humanos necesarios para ejercer la violencia física o impedirla por el ejercicio o amenaza (respaldada por una capacidad efectiva) de ejercer la violencia física.

Por último, el poder cultural se funda en el control efectivo de los conocimientos necesarios para formar la capacidad de acción de los hombres. El poder cultural, al igual que los otros dos poderes, no se basa en el engaño, sino en el control de conocimientos verdaderos que los otros hombres necesitan para formar su capacidad de conocer y de actuar. Por lo mismo, la capacidad coercitiva del poder cultural no es simbólica o imaginaria, sino que sus efectos son materiales, ya que los hombres no pueden actuar sin formar a través de la comunicación sus capacidades de acción.

Estos tres tipos de poder no existen independientemente, sino que están mutuamente imbricados en una relación sistémica de dependencia técnica recíproca. Cada tipo de poder se funda en los tres tipos básicos de acción. Y cada uno de los tres tipos básicos de acción no puede producirse sin

(21) M. Weber, ibid, p. 43

(22) T. Parsons, El sistema social, Revista de Occidente, Madrid, 1976, pp. 120, 121.

(23) M. Mann, Las fuentes del poder social. Alianza Editorial, Madrid, 1991. Cap I Este autor agrega una cuarta fuente de poder, la capacidad de organización. Sin embargo, creo que esta cuarta fuente no es tan básica como las otras tres, ya que la organización sólo existe por la aplicación de conocimientos económicos y políticos y por la comunicación de conocimientos. Pero, de todos modos, la eventual aceptación de la existencia de esa cuarta fuente de poder no cambia en nada el razonamiento que aqui planteo los outputs de los otros, al tiempo que los outputs de cada una son necesarios como inputs de las otras. Por esta razón cada forma de acción y por ende cada tipo básico de poder se encuentra sistémicamene articulado con los otros.

\section{RELACIONES DE PODER Y DESARROLLO DE LAS FUERZAS PRODUCTIVAS}

Todas las acciones, políticas, económicas y culturales necesitan para ser realizadas recursos materiales (24). Puesto que los recursos materiales a disposición del hombre dependen de las fuerzas productivas, resulta que el grado y tipo de desarrollo de éstas condiciona el conjunto de las acciones sociales. En este sentido el grado y tipo de desarrollo de las fuerzas productivas delimita el campo de las acciones materialmente posible. Este campo establece los límites más allá de los cuales ninguna acción en función de fines es realizable en un momento determinado.

El condicionamiento de toda acción, política, económica y cultural, por el campo de lo materialmente posible determinado por el grado y tipo de desarrollo de las fuerzas productivas, fue planteado por Marx en el Prefacio a la Crítica de la economía política (25).

Esto ha dado lugar a una interpretación tecnicista del marxismo defendida recientemente por Cohen. Según este autor las fuerzas productivas «seleccionan» las acciones y relaciones sociales, ya que éstas son de una determinada manera en un determinado momento porque son funcionalmente adecuadas al uso y desarrollo de las fuerzas productivas, dado el nivel de desarrollo de éstas en ese momento (26).

El problema de esta explicación de la relación entre fuerzas productivas y acción social es que no explica ni la causa ni la función de las fuerzas productivas. Por lo tanto no explica lo que determina técnicamente las fuerzas productivas ni cómo se produce su selección (27).

Ahora bien, si se analiza la causa y la función de las fuerzas productivas resulta que la afirmación según la cual las relaciones sociales son seleccionadas por su adecuación al desarrollo de las fuerzas productivas es falsa. Al contrario, son las relaciones entre los hombres, y más exactamente las relaciones de poder entre los hombres, el mecanismo en el cual se produce la selección causal y funcional de las fuerzas productivas, ya que en las relaciones de poder se producen y se seleccionan las capacidades de acción y las acciones que causan las fuerzas productivas y las necesidades o fines que determinan la adecuación técnica de las fuerzas productivas.

Esto no quiere decir que los hombres puedan existir y actuar, en algún terreno o tipo de acción, o aspecto de las acciones, sin plegarse a las exigencias de la técnica.

(24) M. Weber, Essais, op. cit., p. 139.

(25) K. Marx, Contribution à la critique de l'économie politique, Ed. Sociales, París, 1977, pp. 2-3. Le Capital, op. cit., Vol. III, p. 717.

(26) G. Cohen, La teoría de la historia de Karl Marx. Una defensa. Ed. Pablo Iglesias y Siglo XXI de España, Madrid, 1978, pp. 31, 177 y 179.

(27) J. Elster, El cambio..., op. cit., pp. 24, 55 y 56. 
Pero del hecho de que toda acción humana esté necesariamente determinada por la adecuación técnica de los medios a los fines no se desprende que la acción del hombre sea seleccionada por su adecuación técnica al desarrollo de las fuerzas productivas.

Las fuerzas productivas no son otra cosa que la capacidad de conocer y de actuar sobre los hombres aplicada a la producción de recursos materiales. Ningún objeto material existe como fuerza productiva si el hombre no lo utiliza como medio o como objeto de sus acciones en función de producir algo. Por lo mismo el desarrollo de las fuerzas productivas es efecto del desarrollo de las capacidades de conocer y de actuar de los hombres aplicados a la producción de recursos materiales. Ningún instrumento o medio de producción se desarrolla por sí mismo, sino que su desarrollo es necesariamente efecto de la aplicación de las capacidades de conocer y de actuar de los hombres a los objetos materiales (28). De lo cual resulta que la función que determina la adecuación técnica de esas acciones son las necesidades y fines de los hombres, ya que siendo el hombre la causa de las fuerzas productivas, si no producen y reproducen la capacidad de acción de los hombres, las fuerzas productivas no existen o no se reproducen. Por lo tanto, lo que determina la adecuación técnica de la acción del hombre no es su adecuación al desarrollo de las fuerzas productivas, sino su adecuación técnica a los fines y necesidades de los hombres y a la producción y reproducción de la vida y de la capacidad de acción de los hombres. Esto no se debe a que la técnica no condicione la acción del hombre, sino que se debe precisamente a que la condiciona: la acción sólo es posible si es técnicamene adecuada a producir y reproducir la capacidad de acción del hombre, ya que la causa que produce la acción es la puesta en práctica de esas capacidades. Y como la causa de la existencia y desarrollo de las fuerzas productivas es la acción del hombre resulta que esa existencia y ese desarrollo sólo son técnicamente posibles si las acciones son técnicamente adecuadas a producir la vida y la capacidad de acción del hombre.

Ahora bien, lo que determina causal y funcionalmente el desarrollo de las fuerzas productivas no es sólo la capacidad de acción económica.

El mecanismo por el cual se producen y seleccionan las acciones que causan la capacidad de conocer y de actuar de los hombres es la lucha o competencia entre los hombres. Y la función que determina la adecuación técnica de las acciones con respecto a la producción-reproducción de la existencia y capacidad de acción de los hombres es la adecuación técnica de las acciones para producir-reproducir la capacidad de los hombres de luchar o competir con éxito.

En la medida en que el hombre no vive aislado, sino que vive en relación con otros hombres y dado que los recursos materiales y los conocimientos y capacidades de acción son

(28) K. Marx, Manuscrits de 1857-1858 (Grundrisse), Ed. Sociales, Paris, 1980, Vol I, pp. 33, 34, 36 y Vol. II, p. 194. Véase también M. Godelier, L'idéel et le matériel, Fayard, Paris, 1984, pp. 173-74, 192 y 199s200, y L. Sève, Marxisme et théorie de la personnalité, cap. II, especialmente p. 129. Véase también Cohe, op. cit., pp. 45 a 50 . Las distinciones que hace Cohen entre diferentes fuerzas productivas no cambia el hecho de que todas son necesariamente efecto de la aplicación de las capacidades de conocer y de actuar de los hombres. relativamente escasos, el éxito o el fracaso de las acciones depende de la lucha entre los hombres por la obtención y utilización de los recursos materiales e intelectuales necesarios para existir y actuar. La selección de las acciones adecuadas a producir-reproducir la existencia y capacidad de acción de los hombres puede ser realizada de manera intencional, es decir, de manera consciente o racional. O bien puede producirse por una selección de tipo darwiniana en la cual, independientemente de la conciencia de los actores, el éxito o el fracaso determina qué acciones pueden producirse y cuáles no. $\mathrm{O}$ bien puede producirse una selección intermedia de tipo lamarckiano (29). Pero en todos los casos el éxito o el fracaso de las acciones y la selección consiguiente, no depende sólo de la relación del hombre con los objetos materiales y de su capacidad de transformarlos en recursos, sino también de la lucha o competencia entre los hombres. Esto no quiere decir que los hombres actúen necesariamente con el fin de competir o de dominar a los otros hombres, sino que sea cual sea el fin, aun un fin perfectamente altruista, el éxito o el fracaso de la acción no depende sólo de la relación con el medio ambiente no humano, sino también de la lucha o competencia con los otros hombres por obtener los recursos materiales e intelectuales necesarios (30).

La capacidad de luchar o competir de los hombres es el poder.

El poder económico consiste en el control técnico de las acciones que producen, gestionan y llevan hasta el consumidor los recursos materiales necesarios para la existencia y acción de los hombres. En este control técnico, se funda en parte la capacidad de cada hombre para tener éxito en la competencia o lucha por decidir la orientación del desarrollo de las fuerzas productivas y la distribución de los productos.

Ahora bien, el poder económico no alcanza para tener éxito en la competencia en la que se selecciona el desarrollo de las fuerzas y la distribución de los productos. El poder económico sólo existe por la capacidad de acción de los hombres y esta capacidad de acción no se puede constituir y poner en práctica en la competencia con los otros hombres sin el ejercicio/control de la violencia física, es decir, sin control del poder político. La violencia no crea fuerzas productivas, ya que la violencia sólo puede destruir o proteger. Pero si bien no produce fuerzas productivas, es un mecanismo de selección de los fines y las acciones que causan el desarrollo de las fuerzas productivas, ya que el control de la violencia fisica permite transformar la distribución y utilización tanto de los conocimientos en que se funda la capacidad productiva como de los recursos materiales necesarios para la producción, y por lo tanto constituye una fuente de éxito en la competencia en la que se seleccionan las fuerzas productivas.

Pero no basta con las acciones económicas y políticas para tener éxito en la competencia o lucha. Es necesario también la comunicación de conocimientos. El poder cultural consiste en el control técnico de las acciones necesarias para

(29) L. Paramio, «El materialismo histórico como programa de investigación», en Revista Sociedad, Buenos Aires, núm. 1, p. 31.

(30) M. Olson, Logique de l'action collective, Puf, París, 1978, pp. 87, 88. 
comunicar los conocimientos. La comunicación de conocimientos no produce por sí misma las fuerzas productivas, ya que sin el trabajo productivo los conocimientos no se transforman en fuerzas productivas. Pero el trabajo productivo no existe más que como aplicación de los conocimientos de los hombres. Esos conocimientos y capacidades de actuar no se forman solamente en la comunicación con otros hombres, ya que cada hombre produce conocimientos y capacidades de acción en sus relaciones directas con los objetos y medios de la acción. Pero sin la comunicación de conocimientos el hombre queda librado a su propio aprendizaje y no puede desarrollar las fuerzas productivas más allá de la producción individual sin intercambio y sin división del trabajo. Como además la competencia no implica sólo relaciones económicas, sino también políticas, el éxito en ella no implica solamente conocimientos e informaciones sobre fines y acciones económicas de los otros hombres, sino también conocimientos de lo que los otros hombres están dispuestos y son capaces de hacer mediante el ejercicio de la violencia física. De esta manera la función de comunicación de conocimientos es necesaria para tener éxito en la competencia o lucha por definir fines y acciones y por lo tanto para tener éxito la competencia o lucha en que se decide el desarrollo de las fuerzas productivas y la distribución de los productos.

Esa necesidad de los tres tipos de acciones, cuya eficacia depende de su adecuación técnica, recíproca y a la producción-reproducción de la existencia y capacidad de acción del sujeto de la acción, implica que las relaciones de poder por las cuales se seleccionan las acciones que determinan causal y funcionalmente las fuerzas productivas tienen un carácter sistémico. Las acciones políticas, económicas y culturales constituyen cada una un subsistema de acciones articuladas técnicamente en función de un output específico. La articulación de esos tres subsistemas por el intercambio de outputs/inputs constituye el sistema de la acción. Los recursos materiales son el output del subsistema económico. En tanto que outputs del sistema económico los recursos materiales y las fuerzas productivas que los producen son funcionalmente adecuados si son técnicamente adecuados como inputs del sistema económico, pero también técnicamente adecuados como inputs de los otros subsistemas. $\mathrm{Si}$ no son adecuados a los otros dos subsistemas, éstos no podrán producir sus outputs. Y sin estos outputs el sistema económico no puede funcionar y producir los recursos materiales ya que, sin la comunicación de conocimientos no se produce y no se reproduce la capacidad de conocer y de actuar que causan las fuerzas productivas, y sin el ejercicio control de la violencia física no se mantiene la vida del hombre en que existen esas capacidades productivas. En ese sentido un desarrollo de las fuerzas productivas que no sea adecuado a desarrollar la capacidad de comunicación de conocimientos entre los hombres y la capacidad de ejercer controlar la violencia física sólo puede sobrevivir en una situación en la cual el hombre que las produce no tenga relaciones con otros hombres. En condiciones sociales ese desarrollo de las fuerzas productivas no sobrevive porque no es adecuado para reproducir la :apacidad de quienes las producen de competir ' or obtener los recursos materiales e intelectuales necesarios a su existencia y acción.
Así pues, la competencia o lucha entre los individuos es siempre entre sistemas individuales de acción compuestos por la articulación técnica de los tres subsistemas de la acción. Cada uno de los tres subsistemas existe, se desarrolla y se transforma por la acción del hombre en función de producir un recurso necesario para la acción sistémica. $Y$ en cada uno de esos subsistemas el hombre es capaz de producir transformaciones que a su vez exigen transformaciones en los otros subsistemas (que se producen o no según el resultado de la competencia entre los hombres).

El conjunto de las acciones individuales técnicamente articuladas entre sí y en función de los fines de los individuos que las realizan constituye el sistema social (31). Esta articulación sistémica no es distinta de las relaciones de poder entre los hombres, sino que la selección de las acciones y los fines del sistema se produce por la competencia entre los individuos. Las acciones del sistema son las acciones de los hombres en función de satisfacer sus necesidades y producir y reproducir su capacidad de existir y actuar. La adecuación funcional es, pues, siempre adecuación entre acciones de hombres en función de fines de hombres. En la medida que los hombres tienen desigual capacidad de conocer y de actuar tienen desigual capacidad de producir las acciones del sistema, y por lo tanto tienen desigual capacidad de definir los fines en función de los cuales las acciones se producen y al producirse constituyen el sistema. Si la correlación de fuerzas entre los hombres se mantiene incambiada, es decir, si las capacidades de acción de los hombres no cambian, se reproduce el sistema de acción que causa las fuerzas productivas y en función del cual son técnicamente adecuadas las fuerzas productivas. Pero si cambian las capacidades de acción a nivel político, económico y cultural, cambia la correlación de fuerzas y por lo tanto cambian las acciones que causan las fuerzas productivas y el sistema en función del cual son adecuadas las fuerzas productivas.

De esta manera, la selección de las fuerzas productivas, y más generalmente de todas las acciones, es siempre una selección determinada técnicamente, pero la adecuación técnica está determinada causal y funcionalmente por las capacidades relativas de acción de los distintos individuos, producidas, conocidas, puestas a prueba y seleccionadas o elegidas en las relaciones de lucha política, económica y cultural entre los distintos individuos que con sus acciones hacen existir el sistema social.

\section{PROPIEDAD Y PRODUCCION DEL CAMPO DE LO MATERIALMENTE POSIBLE}

La propiedad de los medios de producción es la institucionalización de las relaciones de poder por las cuales se decide en función de qué necesidades de los actores políticos, económicos y culturales se utilizan y se desarrollan las

(31) Sobre el rol de los fines en la delimitación del sistema, véase N. Luhman, Fin y racionalidad en los sistemas. Madrid, Ed. Nacional, 1983, pp. 47, 150, 166, 174, 176,178 , y P. Narbondo, «Los limites del análisis funcionalista de la acción social», en Revista de Ciencias Sociales, Montevideo, núm. 8, pp. 89-101. 
fuerzas productivas. En tanto que tal, es el mecanismo social, es decir, el tipo de acciones sociales, por el cual se decide de manera legítima y legal la orientación del desarrollo de las fuerzas productivas, y por el cual se accede de manera legítima y legal a los recursos materiales necesarios para la existencia y acción.

Puesto que todo hombre necesita recursos materiales para existir y puesto que toda acción necesita recursos materiales para ser realizada, resulta que la propiedad de los medios de producción constituye una institución estratégica. Las decisiones legítimas y legales que en ella se toman determinan el campo de las acciones políticas, económicas y culturales materialmente posibles, así como el tipo de acciones legales y legítimas adecuadas a la obtención de los recursos materiales que todo individuo, grupo o institución, necesita para existir y actuar. Dada una determinada propiedad de los medios de producción sólo pueden ser realizadas las acciones políticas, económicas y culturales adecuadas al conjunto de recursos materiales cuya producción ha sido decidida en esa propiedad, y sólo se podrá acceder a ellos de manera legítima y legal a través del mecanismo, acciones sociales, que constituye esa propiedad (32). Y para toda acción que no se adecúe a los recursos materiales producidos y a los mecanismos de acceso a ellos, se produce la verificación empírica de que, o bien la acción no puede ser realizada ya que no obtiene los recursos materiales, o bien si se realiza, lo hace mediante la violación del orden y la eficacia productiva de recursos materiales y con ello genera el desorden y la ineficacia en la relación outputs/inputs del conjunto del sistema político, económico y cultural.

Este rol estratégico de la propiedad de los medios de producción se manifiesta actualmente en la capacidad que tienen los inversores privados de generar, con sus decisiones legales y legítimas, una dinámica política, económica y cultural, por la cual se demuestra por verificación empírica, la idea de que la propiedad capitalista existente y el modelo de mercado totalmente libre, es el único adecuado al desarrollo económico, al orden y estabilidad social, a la consolidación de la democracia procedimental y al desarrollo de la racionalidad en la cultura.

El mecanismo de producción de realidad por el cual se verifica empíricamente esa idea es el siguiente:

Cuando la política económica de un gobierno se orienta de manera contraria a las exigencias de los inversores, o cuando una fuerte oposición política y social impide orientar la economía en función de las exigencias de los inversores, se genera el descontento y desconfianza de éstos, lo cual se traduce en el retiro o disminución de las inversiones. Dado que los propietarios individuales tienen el control legal de la mayor parte del capital, y dado que sin inversión de capital no es posible el funcionamiento de la economía, resulta que la orientación contraria a las exigencias de los inversores, o la resistencia a la orientación favorable a sus exigencias, se traduce en crisis económica. Con lo cual se verifica empíri-

(32) A. Przeworski y M. Vallerstein, «Qué está en juego en las actuales controversias en macroeconomía", en J. Labastida y M. del Campo (coords.), Los nuevos procesos sociales y la teoria política contemporánea. Siglo XXI, México, 1986, pp. 54-55. camente que toda orientación de la economía de manera contraria al modelo de capitalismo liberal conduce al fracaso económico, por causas puramente económicas, producidas por medios puramente económicos.

La crisis y estancamiento productivo (o la agravación de ambos) resultante del retiro de las inversiones se traduce, a su vez, en desarrollo del descontento y de las tensiones sociales, caldo de cultivo para utopías y demagogias diversas y para métodos de protesta y lucha más o menos fuera de las instituciones. Con lo cual se verifica empíricamente que toda orientación de la economía contraria al modelo liberal capitalista se traduce en desorden social y en desarrollo de tendencias culturales irracionales con respecto al concepto de orden procedimental legal.

Si ante la constatación de crisis el gobierno rectifica su política económica y la adecúa a las demandas de los inversores, y si el movimiento social modera sus demandas - por estrategia de las organizaciones o simplemente por disminución de las expectativas individuales, o por una mezcla de ambas cosas-, entonces se restablece la confianza de los inversores. Y con ello se restablece la inversión y la actividad económica en la medida adecuada al grado de desarrollo productivo de la sociedad según la opinión y las expectativas de los inversores. En cambio, si el gobierno se plantea tomar medidas legales para limitar el poder de los inversores para decidir la utilización de los medios de producción, esas medidas generan, como es lógico, la desconfianza absoluta de los inversores nacionales y extranjeros y por lo tanto disminuye aún más la inversión y se genera una salida de capitales en busca de lugares más seguros y más rentables. Y lo mismo sucede si el movimiento de oposición a los intereses de los inversores crece de manera que se vuelva posible su acceso al gobierno y con ella a la posibilidad de tomar medidas legales. Esto lleva la ineficacia económica y las tensiones sociales a extremos críticos. Con lo cual se hace más evidente que la orientación de la economía contraria a los intereses de los inversores, aunque se haga por medios legales, conduce a la crisis de la economía y al desorden social.

Si el gobierno persiste en su intento de control legal de las inversiones, o si el movimiento social sigue creciendo y resistiendo a las reformas adecuadas a los intereses de los inversores, entonces resulta claro y evidente que es un gobierno o un movimiento de oposición política y social irracional, ya que no reconocen lo que empíricamente se constata, es decir que su accionar y sus intenciones al generar desconfianza en los inversores generan crisis económica y social.

$\mathrm{Y}$ ante la irracionalidad e irresponsabilidad del gobierno, o de la oposición política y social, que pone en peligro el orden económico y social, se considera legitimada (aunque provisionalmente no legal) la necesidad de restablecer el orden económico y social mediante un golpe de Estado contra el gobierno reformista, o mediante un gobierno autoritario contra la oposición, que tanto temor y desconfianza genera en los inversores nacionales e internacionales.

Como la crisis económica y el desorden social es perjudicial para toda la sociedad se constituye una alianza más o menos explícita, o para nada explícita, de actores con alto 
poder político, económico y cultural, con apoyo, más o menos amplio, y más o menos difuso, de una base social que aspira sobre todo al restablecimiento del orden social y de la actividad económica, que se encarga mediante un golpe de Estado o un gobierno autoritario de restablecer el orden económico y social y la racionalidad en la política. Con lo cual queda verificado empíricamente que todo orden económico que no se adecúe a las exigencias de los propietarios de los medios de producción es incompatible con la democracia procedimental, ya que conduce a la crisis económica, al desorden social y más tarde o más temprano a un golpe de Estado o a un régimen autoritario.

El cual se encarga de crear las condiciones sociales y económicas que restablezcan o creen la confianza de lo sinversores. Con lo cual se restablece la inversión o las perspectivas de inversión, y con ello se restablece el desarrollo, o las perspectivas de desarrollo, económico en los límites y proporciones que corresponde al grado de desarrollo del país o sociedad.

Al mismo tiempo se restablece la moderación y limitación de las expectativas y demandas de los sectores sociales con menos poder, o que han perdido poder en el proceso, lo cual correlativamente permite satisfacer los intereses de los sectores con más poder, o que han ganado poder adecuando sus acciones al proceso. Y con ello se restablece el orden y el equilibrio social en la medida y en la proporción que a cada cual corresponde según su capacidad de acción política, económica y cultural.

$Y$ en la medida que se restablece el orden y equilibrio social y la cordura y racionalidad de las expectativas se vuelve posible satisfacer las demandas de retorno a la democracia. Con lo cual se verifica empíricamente que el retorno o la instauración de la democracia procedimental sólo es posible con una economía y con una cultura política y social fundada en el respeto de la propiedad capitalista. Y si en algún momento de la transición o del futuro se replantean las dudas sobre ese aprendizaje, y si esas dudas no se autolimitan al mero pensamiento utópico, sino que pretenden conocer y poner en práctica medios alternativos y orientaciones distintas de la economía, recomienza el proceso de demostración empírica por vías legales, y menos legales si es necesario, de las consecuencias económicas, sociales y políticas de la pérdida de la confianza de los inversores nacionales e internacionales.

Como esto ya está aprendido y duramente aprendido, el poder de chantaje de los inversores (en el sentido que le da Sartori con respecto a los partidos) (33), surte efecto. El pensamiento de las alternativas tiene tendencia a limitarse al sueño justo de las utopías, mientras que el conocimiento teórico-empírico (político, económico y social) tiene tendencia a limitarse a transitar las vías adecuadas y compatibles con los fines e intereses definidos por los sectores que controlan la estructura de poder político, económico y cultural (34).

(33) G. Sartori, Partidos y sistema de partidos. Alianza Ed., Madrid, 1980, p. 157.

(34) O'Donnell y Schmitter, «Conclusiones», en G. O'Donnell, Schmitter, Transiciones desde un gobierno autoritario, Paidós, Buenos Aires, 1989, Vol. 4, pp. 15, 16,
Con lo cual se consolida el orden social y la racionalidad de la cultura política y social. Y con ellos se consolida la democracia procedimental. Con lo cual a su vez se verifica empíricamente que la consolidación de la democracia procedimental sólo es posible con una economía y con una cultura política y social que respete la propiedad capitalista y las exigencias e intereses de los inversores privados.

Este mecanismo no es, ni mucho menos, el único que causa las crisis económicas y sociales y las rupturas y restauraciones de la democracia (ni los inversores el único grupo con alta capacidad de «chantaje»). Pero es uno de los mecanismos, y es un mecanismo fundamental por el que se establece el campo de lo materialmente posible y con ello se establece el referente material por el cual se verifica empíricamente la racionalidad y verdad del pensamiento sobre acciones y fines y sus efectos sobre el hombre y el medio ambiente. ( $\mathrm{Y}$ este mecanismo se produce también a nivel de las relaciones internacionales.)

\section{PROPIEDAD DE LOS MEDIOS DE PRODUCCION Y RELACIONES DE PODER}

Así, pues, en la producción de la realidad social, la propiedad de los medios de producción constituye una institución estratégica ya que en ella y por su control se decide la orientación y el uso de la producción material, y con ello se crea el campo de las acciones y de los fines políticos, económicos y culturales materialmente posibles.

Ahora bien, la propiedad como toda institución y como toda la sociedad sólo existe por la acción de los hombres en función de sus fines y necesidades. Como éstos no constituyen un todo único, sino que son individuos con distintas capacidades de conocer y actuar y con distintas necesidades y fines, la propiedad, como todas las instituciones, es resultado de la capacidad de acción de los distintos individuos puesta a prueba y seleccionada en las relaciones de lucha o competencia entre los individuos, es decir, es resultado de las relaciones de poder político, económico y cultural por las cuales se seleccionan los fines y necesidades y con ellos los medios y las acciones y las instituciones técnicamente adecuadas.

En esas relaciones de poder para que una forma de propiedad se estabilice es necesario que sea adecuada a la realización técnicamente correcta de la gestión y producción de los recursos materiales. Pero quién o quiénes sean los pro-

110,111 . Véase también en la misma obra colectiva A. Przeworski, «Algunos problemas en el estudio de la transición), Vol. 3, pp. 102, 103. No se trata de negar validez a la opción de centrar el estudio en los temas estrictamente politi$\cos$. Creo que metodológicamente es una opción que ha producido importantes aportes al estudio de la democracia y de las transiciones. Creo también que la democracia normativa es, en tanto que tal, un medio y un fin deseable y necesario (en el sentido de adecuado, no en el sentido de que se ha de producir necesariamente en el devenir) para la vida y acción de los hombres. Pero el hecho de que para instaurarla o reinstaurarla, se plantee como necesario que tanto los actores sociales (vol. 4, pp. 110-111) como los autores de una de la obras más importantes y representativas del pensamiento politico de los años ochenta (ibid, pp. 1516), deban asumir que es necesario renunciar a poner en cuestión las relaciones de propiedad es sintomático de la capacidad y del poder de los inversores o propietarios de los medios de producción para delimitar el campo de la acción posible y racional y del conocimiento empirico posible, útil y aceptable en cada momento. 
pietarios y cómo se acceda a esta propiedad, y por lo tanto quién o quién y cómo decidan el uso y desarrollo de los medios de producción depende y es resultado de las relaciones de poder.

En ese sentido la experiencia del propio capitalismo, a lo largo de su historia y en los distintos países, demuestra que la gestión económica correcta y el desarrollo económico se puede lograr con distintas combinatorias de diversas formas de propiedad y con una orientación distinta en cuanto al tipo de (y de quiénes) necesidades e intereses que se busca satisfacer. Concretamente la experiencia histórica demuestra que la intervención del Estado en la gestión económica, en la producción y en lo social, no son incompatibles con el desarrollo de la riqueza material, sino que, en determinadas condiciones y en función de determinados intereses y necesidades, es perfectamente adecuada, y con alto grado de duración y estabilidad del éxito (35). Determinadas condiciones y necesidades que no todas las sociedad ni todos los sectores sociales han superado y satisfecho en la actualidad.

Pero ciertamente ese modelo, como toda acción o conjunto de acciones, no es adecuado para todas las condiciones y para todas las necesidades o intereses. Ahora bien, el modelo de propiedad y de orientación del desarrollo de las fuerzas productivas que lo reemplace sólo se puede conocer y poner a prueba en el proceso de lucha política, económica y cultural de los hombres en función de la satisfacción de sus intereses y necesidades. En ese sentido la idea neoliberal según la cual la liberalización total del mercado y la propiedad capitalista existente, es el tipo de gestión y el tipo de propiedad adecuado a los intereses y necesidades de los hombres en la actualidad, es una creencia, que ha sido y es formulada en hipótesis fundadas en conocimientos empíricos, pero que aún no se conocen ni se han verificado empíricamente los efectos que tendrá su puesta en práctica sin limitaciones sobre la existencia y capacidad de conocer y de actuar de los hombres y sobre el medio ambiente. Los éxitos económicos, culturales y políticos alcanzados por los países desarrollados no pueden ser atribuidos a ese modelo, ya que lo que ahora existe, en sus virtudes y defectos, es efecto del modelo Estado-céntrico que el neoliberalismo se plantea desmantelar y reemplazar. Es decir, el equilibrio social, el desarrollo educativo, el desarrollo productivo, los niveles de salud y sanidad, etcétera, que caracterizan las sociedades desarrolladas actuales no son efectos del modelo neoliberal, sino del Estado Keynesiano y de Bienestar. ( $\mathrm{Y}$ en América Latina, el desarrollo social, cultural e industrial fue producido [lo cual no elimina ni borra sus defectos y errores] por los regímenes populistas, o por Estados intervencionistas en lo económico y en lo social como el batllista [con sus errores y defectos]).

En cuanto al modelo neoliberal, puesto que todavía no ha sido aplicado plenamente, todavía no se ha demostrado empíricamente que sus efectos sean adecuados a producir reproducir la existencia y capacidad de acción de los hombres de manera exitosa y satisfactoria para los distintos indi-

(35) L. Paramio, Tras el diluvio. Siglo XXI, Madrid, 1988, pp. 117-131, y R. Muñoz del Bustillo (comp.), Crisis y futuro del Estado de Bienestar. Alianza Editorial, Madrid, 1989. viduos. Y lo que por ahora se puede constatar empíricamente no es nada alentador en terrenos como, por ejemplo, la utilización productiva del capital, la disminución de la pobreza, la ampliación social y profundización del desarrollo cultural, o el desarrollo de la autonomía de los hombres, o sea esto último: el desarrollo del poder de cada individuo para participar autónomamente en la producción política, económica y cultural de la sociedad en la que vive (36). Lo cual no significa que al mismo tiempo el modelo neoliberal, en la medida que es aplicado, no logre éxitos que constituyen la verificación empírica de las hipótesis en que se funda, o de parte de esas hipótesis. Pero el tipo de éxito y cómo se distribuyen sus resultados, que se van constatando constituyen, también, la verificación empírica de en función de qué tipos de necesidades e intereses, y de qué tipos de individuos (es decir, con qué tipo y grado de capacidad relativa de conocer y de actuar) es adecuado el modelo neoliberal. Y no se trata de los costes del ajuste necesario para aumentar el ahorro y la inversión, sino de cómo se distribuyen esos costes y los beneficios, y cómo y quiénes controlan el ahorro y en función de qué necesidades y fines se realizan las inversiones (37).

En ese sentido, el modelo neoliberal y la propiedad capitalista tal como existe actualmente, como todo modelo de acción y propiedad, no puede ser adecuado para todas las condiciones y para todos los fines y necesidades de los hombres, ya que toda acción está necesariamente condicionada técnicamente y por lo tanto es adecuada en determinadas condiciones y en función de determinados fines. $Y$ esas determinadas condiciones y fines, en las cuales y en función de los cuales cualquier modelo político, económico y cultural es o no es adecuado, sólo existen por las acciones en función de las necesidades y fines de los hombres producidas, conocidas, puestas a prueba y seleccionadas en las relaciones de poder político, económico y cultural. [Véase M. Weber (38).] Y esas relaciones de poder no son relaciones sólo de actores económicos, o en última instancia de actores económicos, sino que todos los individuos participan en esas relaciones, ya que todos necesitan y como tal actúan en función de obtener los recursos materiales, y con esas acciones participan en la producción, reproducción o transformación de la institución que constituye la propiedad.

(36) L. Paramio, «Democracia política y neoliberalismo», en Etcétera, México, febrero 1993, núm. 1, pp. 18-23. Claude Julien, "Complices ou insurgés? Le liberalisme contre la société", en Le Monde Diplomatique, diciembre, 1993, pp. 1 y 16-17.

(37) A. Przeworski y M. Vallerstein, "Qué está en juego...», op. cit, p. 48.

(38) M. Weber, Essais, op. cit. pp. 442-443: «Una cosa es en todo caso indudable: cuando se trata de apreciar una reglamentación de las relaciones sociales, cualquiera que sea su naturaleza, es necesario siempre, sin excepción, examinarla desde la siguiente perspectiva: $¿$ a qué tipo de hombres proporciona mejores posibilidades de dominación por el juego de los factores subjetivos y objetivos de selección?». Véase también ibid. pp. 458-459: "Se ha creído posible deducir evaluaciones univocas en particular de orden económico... [pero esta creencia] ignora la existencia de clases sociales cuya situación puede (no digo: debe) deteriorarse absolutamente bajo el régimen de libertad de mercado, por el hecho de que el poder de compra de ciertas capas de consumidores puede disminuir no solamente a pesar de la repartición "óptima" entre el capital y el trabajo en las diferentes ramas de la producción, sino precisamente a causa de ella. En efecto, la distribución "óptima" de la rentabilidad que condiciona la constancia de las inversiones de capitales depende, a su vez, de la constelación de fuerzas entre las diversas clases, y las consecuencias de esos fenómenos pueden (no digo: deben) debilitar en una situación concreta la posición de esas capas sociales en la batalla de los precios.) 


\section{A MODO DE CONCLUSION: REALIDAD SOCIAL, RELACIONES DE PODER Y LIBERTAD Y RESPONSABILIDAD DE LOS HOMBRES}

La realidad social, en tanto que sólo existe por la acción de los hombres, es resultado del poder de los hombres, es decir, de la capacidad relativa de acción de los hombre. Como tal, la realidad social se adecúa y da la razón a los intereses o fines de los individuos que en la lucha política, económica y cultural han tenido éxito en la defensa de sus fines o intereses.

En esa lucha los hombres sólo pueden tener éxito si sus acciones son técnicamente adecuadas a nivel político, económico y cultural en función de sus propias necesidades y en función de la lucha o competencia con las acciones e intereses de los demás hombres. Por lo tanto, los hombres no pueden escapar nunca al condicionamento técnico, ya que sin la adecuación técnica de sus acciones en función de sus fines y de la competencia con otros hombres, su acción fracasa y por lo tanto no alcanza sus fines.

Pero los hombres tienen la capacidad de desarrollar sus capacidades de conocer y de actuar a nivel político, económico y cultural. Por lo tanto, tienen la capacidad de cambiar la correlación de fuerzas en las relaciones de poder político, económico y cultural que producen, reproducen o cambian la realidad social y las instituciones.

$\mathrm{Y}$ en esas relaciones de poder, todo hombre es libre, según sus conocimientos y sus capacidades de conocer y de actuar, y por ende responsable, para decidir cómo y en función de qué fines y necesidades utiliza sus conocimientos y capacidades de conocer y de actuar.

Pero cualquiera que sea la decisión nadie puede escapar a las consecuencias de las acciones producidas, o a las consecuencias de la no producción de las acciones.

En ese sentido, una sociedad en la que predomina, por un lado, la definición de la izquierda de sus ideales como expresión utópica de deseos y creencias válidos en sí mismos, pero impotentes a nivel de realización, y, por el otro lado, la pretensión de la derecha de que la razón instrumental sólo se puede utilizar para desarrollar el poder y para satisfacer los intereses de los más fuertes, sumado a una creciente marginación de los que tienen menos capacidad política, económica y cultural, puede conducir, y de hecho está conduciendo a: por un lado, la pérdida de poder relativo y la desmotivación de la base social de la izquierda; y, por otro lado, al surgimiento o resurgimiento y crecimiento en algunos marginados de la idea de que sus deseos de identidades puras con connotaciones xenófobas o racistas, por las cuales se aferran simbólicamente a la sociedad que de hecho los excluye material y culturalmente, son en sí mismos tan válidos como cualquier otro deseo, y que la violencia contra todo aquel que sea más débil es el instrumento adecuado (porque es el que tienen a su alcance y están en condiciones de utilizar), para hacerlos realidad.

Probablemente estos últimos no tendrán éxito, porque la violencia pura no es un instrumento adecuado (dado que la acción social es necesariamente sistémica) para tener un éxito sólido y estable. Pero el hecho de que lo intenten constituye un caldo de cultivo y proporciona una base social para el surgimiento de líderes y movimientos con un discurso demagógico que promete la satisfacción de todos los deseos sin especificar medios y consecuencias de su satisfacción y que puede ir acompañado (pero no necesariamente, ya que también pueden surgir líderes y movimientos de izquierda con discursos vagos y demagógicos no autoritarios), con un discurso y una práctica de restablecimiento del orden por medios violentos y autoritarios contra las tentativas de transformar la sociedad en el sentido de un mayor equilibrio de poder. Y esa base social no está formada sólo por los marginados y no marginados violentos, sino también por los que (incluso dentro de los sectores que constituyen, o han constituido, la base social de la izquierda) desean orden y seguridad en una sociedad que perciben como violenta y peligrosa para los débiles.

Quizá esos líderes y movimientos no tengan éxito. Pero el hecho de que la sociedad, en diversos sectores, sea receptiva a ese tipo de actitudes e ideologías y la acentuación de las tendencias excluyentes del desarrollo son efectos del sistema político, económico y cultural suficientemente graves para plantearse la conveniencia y la utilidad (y no por altruismo, sino por el interés de no tener que aceptar y adecuarse a las tendencias autoritarias y excluyentes) (39) de orientar la producción y utilización de los conocimientos empíricos y de las capacidades de actuar en función de satisfacer las necesidades de los sectores con menos poder y, sobre todo, en función de desarrollar su poder relativo, es decir, su capacidad política, económica y cultural, de defender sus intereses. Esto último es lo fundamental, ya que si no cambia la correlación de poder la redistribución en función de los sectores sociales más desfavorecidos sólo se puede realizar con los sobrantes que no interesan y no encuentran demanda en la estructura de poder existente, y por las vías y métodos adecuados o compatibles a su reproducción. Querer transformar la estructura de satisfacción de las necesidades de los distintos individuos que componen la sociedad sin transformar la estructura de poder es pura utopía (o como decía Marx, puro donquijotismo) (40), es decir, una idea teoría que no se da en los medios de su realización.

Y no sólo es necesario la defensa y conservación de las conquistas sociales ya obtenidas, sino que es necesario, también, un accionar ofensivo que ante los nuevos problemas y demandas y ante la transformación de las condiciones socia-

(39) No se trata de una alternativa entre orientar la acción por intereses u orientarla por ideales. (Véase J. Habermas, Teoría de la acción comunicativa. Taurus, Madrid, 1987, vol. I, p. 251). Los ideales sólo pueden dar sentido a la acción en tanto que pensamiento de un interés o conjunto de intereses de los hombres. Un ideal que no determine un objeto o un conjunto de objetos como deseados o buscados por la voluntad es un ideal completamente determinado y como tal no puede dar ningún sentido a la acción y a la existencia (véase M. Kant, Crítica de la razón práctica, Espasa-Calpe, Madrid, 1981, pp. 56, 157, 181, y Crítica de la razón pura, op. cit, pp. 157,181, 261, 264, 272, 300, 348-353). Inversamente, todo interés es una elección práctica, y como tal determinado por los valores ideales, o mundo de la vida, del hombre que elige esos intereses. (Véase M. Kant, Crítica de la razón práctica, op. cit., pp. 38 a 42 y 171 , y Métaphysique des moeurs. Première partie. Doctrine du droit, J. Vrin, París, 1979, p. 86). Por lo tanto, la alternativa no es entre ideales o intereses, sino entre distintos tipos de ideales e intereses en función de los cuales cada hombre elige desarrollar y utilizar sus capacidades de conocer y actuar.

(40) K. Marx, Grundrisse, op. cit., Vol. I, p. 95, y L'idéologie Allemande. Ed. Sociales, París, 1976, p. 39. 
les, plantee e impulse soluciones técnicamente adecuadas en función de desarrollar el poder de los sectores sociales más débiles y desfavorecidos.

En esta perspectiva no me parece que la buena dirección sea la de buscar un Estado pequeño fuerte (41) si el empequeñecimiento y el fortalecimiento se produce por reducción de los recursos de poder económico y culturales que permiten a un Estado democrático orientar el desarrollo en función de mayor cohesión social y equilibrio de poder. La fuerza de un Estado se basa en los recursos de poder que controle y en los apoyos sociales que tenga. Si se reducen los recursos de poder económico y cultural que el Estado controla, su poder queda reducido a la función de ejerciciocontrol de la violencia legítima, o sea, a la función de Estado-gendarme. Con esto su lógica de acción y de mantenimiento de su poder queda ligada al cumplimiento de esa función. Con lo cual el tipo de apoyo que puede conseguir es el de aquellos sectores sociales que por tener poder económico y cultural sólo necesitan al Estado para hacer respetar, mediante la violencia legítima, las normas y valores que regulan y legitiman la estructura de poder existente, y de aquellos sectores sociales ligados al cumplimiento de las funciones de ejercicio-control de la violencia. Y también de sectores populares que dada la precariedad y precarización de su situación demandan y aceptan orden y estabilidad política y económica, aunque el precio sea que el punto de equilibrio económico implique alta concentración de los beneficios y del poder en los sectores sociales más poderosos y, correlativamente, fuerte disminución de la participación en los beneficios y en el poder de los sectores más débiles (42).

Ahora bien, como el Estado no puede (ni creo que sea deseable que pueda) cumplir todas las funciones, y como la experiencia demuestra la necesidad del mercado, creo que es necesario - además de defender y desarrollar un Estado democrático que no se reduzca a la función de control-ejercicio de la violencia legítima - plantear e impulsar en los terrenos en que el mercado funcione como agitador de recursos la puesta en práctica de: a) mecanismos de control público y democrático de las inversiones y de la gestión decididas e implementadas por empresarios con autonomía ejecutiva, pero responsables ante los órganos de control democrático; b) mecanismos legalmente obligatorios que establezcan la participación de los asalariados en los dividendos de las empresas (además del salario); y c) mecanismos legalmente obligatorios de participación de éstos en la propiedad de las empresas en las que trabajan, y en otras mediante fondos de inversión que canalicen hacia la inversión parte de los dividendos (no del salario) correspondientes a los asalariados. El punto «c)» con el fin de ligar los intereses de éstos no sólo a la distribución inmediata bajo forma de salarios o dividendos, sino también a la inversión, ya que alparticipar en la propiedad de las empresas la inversión aumenta el valor de sus patrimonios. Y para garantizarles que los recortes de sus ingresos en los períodos de reducción de costos y de aumento de la inversión, se traducirán obligatoria y automáticamente - ya que propietarios legales de parte de lo

(41) L. Paramio, «Democracia política y liberalismo», op. cit., p. 23. (42) O'Donnell, p. 23. ahorrado e invertido-, en ingresos para ellos cuando las empresas, y la economía en general, vuelvan a dar dividendos (43).

Y no se trata de que alguna teoría aplicada a la acción pueda eliminar las relaciones de poder y la generación de desigualdades. Creo, con M. Weber, que toda acción social implica relaciones de poder, y que pretender eliminarlas es pura utopía. Pero no es ninguna utopía que los hombres desarrollen y utilicen sus conocimientos y capacidades de acción para luchar por los recursos de poder necesarios para decidir su existencia y acción. Y no es ninguna utopía que en esa lucha se puede producir un mayor equilibrio de poder entre los hombres (como también se puede producir lo contrario) y con ello el aumento de la capacidad de los que han desarrollado su poder para obtener la satisfacción de sus necesidades, y la disminución, correlativa, de su dependencia de la buena voluntad o del altruismo de otros hombres.

A priori, es decir, antes de la verificación empírica, ninguna teoría puede considerar demostrado que las acciones que a partir y en función de ella se producen son las adecuadas al desarrollo de un mayor equilibrio de poder entre los individuos. Pero si la teoría se limita a la crítica o se refugia en la mentalidad utópica que no acepta el cuestionamiento empírico de sus modelos ideales y que no es capaz de conocer y diagnosticar correctamente problemas, medios y condiciones sociales nunca podrá ser puesta en práctica y, por ende, no podrá ser contrastada empíricamente, y no se podrá aprender de los errores y aciertos, y rectificar medios y fines si así corresponde. Con esa autolimitación tendrá garantizada su validez eterna, pero también su impotencia eterna.

Y sin una decisión —que es necesariamente decisión de individuos en última instancia libres según sus conocimientos y sus capacidades de conocer y actuar, y por lo tanto responsables - de utilizar éstos para luchar y competir en función de producir la realidad de la estructura de poder político, económico y cultural en la cual se fundan y se costrastan empíricamente los conocimientos sociales, las teorías sobre la posibilidad y utilidad de un mayor equilibrio de poder entre los individuos y sobre los medios y fines para desarrollarlo, seguirán siendo o se volverán (como, según dicen, el Estado de Bienestar) «en este momento» utopías. Y la realidad seguirá dando la razón a los que dicen que «en este momento» la única vía de acción posible es utilizar las capacidades de conocer y actuar para adecuarse a las exigencias (directas o indirectas a través del conjunto de acciones por las que existe y se reproduce el sistema social) de los más poderosos política, económica y culturalmente. $Y$ todos seguirán coincidiendo que en el futuro quizá será posible un mayor equilibrio en la distribución del poder y de los beneficios políticos, económicos y culturales. Pero ya se sabe, cuando el futuro llega se transforma «en este momento».

(43) Véase al respecto A. Nove, La economía del socialismo factible. Ed. Pablo Iglesias y Siglo XXI, Madrid, 1987, y A. Przeworski y M. Wallerstein, op. cit., p. 53 «La mejor definición del problema subyacente a la alternativa que enfrentamos aparece en una conferencia de 1973 de los sindicatos irlandeses: "Se le debe garantizar a los obreros que su restricción salarial servirá para realizar inversiones productivas y benéficas y no para incrementar aún más el ingreso personal de la sección privilegiada de la sociedad". Alguna garantía de esta indole es una condición necesaria para el compromiso democrático.» 